\title{
Influence of ecological variation across Pistacia altantica on fruit oil content
}

Bayzid Yousefi

Kurdistan Agriculture and Natural Resources Research Center PO Box 714, Sanandaj, Kurdistan, Islamic Republic of Iran

\begin{abstract}
In the western and central parts of Iran, there are more than eight million female trees of Pistacia atlantica Desf. with approximately 20,000 tons of fruit oil production ability. In order to evaluate the influence of select ecological characteristics, fruit samples of seven $P$. atlantica habitats in Kurdistan (Iran) were collected in late October over two years (2013-14). Fruit oil was extracted using soxhlet extraction. The results showed a relatively small variation in oil content in fruit across plants of $P$. atlantica. The fruit oil content ranged from $25.4 \%$ to $28.4 \%$, with a mean of $27.3 \%$. Most habitats belonged to temperate and semi-arid regions, with higher longitude and altitude but less latitude and slope, higher soil electrical conductivity, total neutralizing value, organic carbon and clay, medium yearly rainfall, evaporation and sunny hours and also trees with medium ages such as Borban and Kashtar producing higher fruit oil yield than those that belonged to cool and semi-humid regions. Cluster analysis classified habitats into four distinct groups at 50\% similarity; four habitats belonging to forest areas were located in the first, Borban and Kashtar in the second and third and Abdolmomen, with the coldest climate and the oldest trees, was in the fourth group. The results of principal component analysis (PCA) revealed that habitats with low fruit oil showed extreme values of $\mathrm{PC}_{1}$ and $\mathrm{PC}_{2}$ but ones with high fruit oil were located mainly in the central zones of the bi plot, which suggest that habitats with medium ecological conditions produce higher fruit oil.
\end{abstract}

Key words: environmental conditions, fruit quality, habitat, pistachio tree

\section{INTRODUCTION}

The genus Pistacia includes many species widely distributed in the Mediterranean and Middle Eastern areas and belongs to the Anacardiaceae family (Ben Douissa et al. 2005). Large populations of Pistacia grow wild in different parts of Iran. There are three species of the pistacia genus in Iran: Pistacia avera, P. atlantica and P. khinjuk (Karimi et al. 2009). The atlantica species has been postulated to have three subspecies: mutica in the middle and south of the Zagros mountains, kurdica mainly in Kurdistan (Zoh.) Rech. and cabulica in the northeast of the country (Khatamsaz 1988). Pistacia atlantica Desf., which is called "Baneh" in Iran, is a multipurpose tree, a drought-tolerant species that is adapted to semi-arid and arid areas (Rowshan et al. 2013). Because of its economic properties, $P$. atlantica is one of the most economically and ecologically important wild species in many rural areas. It plays a considerable role in the rural society's extension, especially in the west of Iran (Razavi 2006, Pourreza et al. 2008). P. atlantica is long-lived and dioecious, with male and female trees producing different types of flowers. Both types are small and greenish and 
are located in simple or compound clusters and fall away quickly. Monoecious and hermaphrodite trees have been seen but are unusual (Isfendiyaroglu and Ozekera 2009). The trees grow up to $7 \mathrm{~m}$ (23 ft.) in height, with branches spreading and growing erect to form a dense crown. The oblong, fleshy, oily and aromatic fruit borne by the female tree are 6 to $8 \mathrm{~mm}$, long and pink in color, ripening blue. In Iran and Kurdistan province, late October to November is the ripening time of $P$. atlantica fruit. There are many uses for this plant. The resin and fruit oil were historically used for a variety of medicinal purposes. It is the source of traditional medicinal agent "gum" mastic, an oleoresin exudate from the stem of this plant (Dogan et al. 2003). Investigations have shown some pharmacological effects such as reducing blood pressure (Villar et al. 1987), upper abdominal discomfort, stomachaches, dyspepsia and peptic ulcer, anti-inflammatory and antimicrobial action (Farhoosh et al. 2009, Ghalem and Mohamed 2010, Tohidi et al. 2011). P. atlantica is often used as a rootstock for pistachio ( $P$. vera) (Ibrahim et al. 1984, Ruelas Garcia 1990). The fruit of $P$. atlantica is an important source of food, although the fruit are smaller and not as commercially valuable as those produced in orchards (Zangeneh 2003). Farhoosh et al. (2011) noted that the fruit oil of $P$. atlantica, which is called Bene Hull Oil (BHO), has been recently introduced to the world as a highly stable compound with anti-oxidative properties. The components of BHO include $6.5 \%$ unsaponifiable matter (common in vegetable oil), carotenes, tocopherols and alcohols. Tocopherols and tocotrienols have antioxidant activity and act similarly to vitamin E, which is beneficial for human health (Mezni et al. 2014). Tanideh et al. (2014) showed that a high dose of $P$. atlantica fruit oil, administered orally and rectally, can improve colitis physiologically and pathologically in a rat model and may be efficient for ulcerative colitis. The studies of Arefi et al. (2003 and 2006) have shown that $P$. atlantica fruits contain valuable oils, including 19 to $39 \%$, especially unsaturated oils, and is suitable for human consumption. Benhassaini et al. (2007) stated that the fruit oil content of $P$. atlantica is more than $39 \%$, with valuable fatty acids such as oleic $(54.2 \%)$, linoleic $(28.8 \%)$ and palmitic $(12.2 \%)$ acids. Oleic acid was the major fatty acid (more than $40 \%$ ), followed by palmitic (22.3-28.6\%) and linoleic (13.6-20.5\%) acids (Mezni et al. 2014). The fruit oil of $P$. atlantica has been reported by Hossein-Khan and Farhang (1996) to be about $30 \%$. In the food industry, there is a tendency to search for new sources of oil that may have nutritional value. $P$. atlantica fruit oil has potential uses as a source for edible oil, as well as for the pharmaceutical and oleo chemical industries (Soad et al. 2014).

In Iran, the use of $P$. atlantica is usually focused on its resin or gum and the oily and aromatic fruits have not been used considerably. Large populations of $P$. atlantica grow wild in different parts of Iran; for example, there are more than 400,000 over 10-year-old female trees only in Kurdistan province (Yousefi 2002), thus, the project of $P$. atlantica fruit oil extraction can provide a new medicinal and edible oil source. Considering this, the present research was performed to compare $P$. atlantica fruit oil production in various habitats to evaluate the influence of select important ecological characteristics on the oil contents of fruits.

\section{MATERIAL AND METHODS}

The research was conducted in seven $P$. atlantica habitats in Kurdistan province in the west of Iran (Fig. 1) including: Marivan, Sarv-Abad, Kamyaran, Sanandaj, Saghez, Baneh1 (Allout) and Baneh2 (Khori-Abad) during two years (2013-14). After recording climate factors such as temperature, rainfall, freezing days etc., some chemical characteristics of soil were recorded by analysis of the soil samples (at $0-60 \mathrm{~cm}$ depth) in every habitat by the soil science laboratory of the Agricultural and Natural Resources Research Center of Kurdistan province. For this, the soil's level of acidity $(\mathrm{pH})$ was measured using a $\mathrm{pH}$ meter, soil organic carbon (OC) using the Walkley-

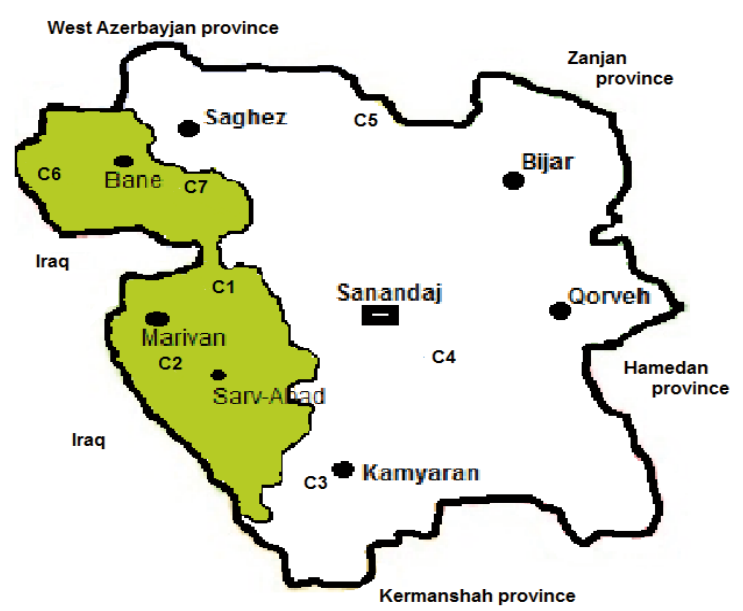

Figure 1. The $P$. atlantica habitats $(\mathrm{C} 1-\mathrm{C} 7)$ on the map of Kurdistan province (green color denotes forest areas) 
Black method (1934), electrical conductivity of the soil extract (EC) using an EC meter (CDM 210), lime material or soil total neutralizing value (TNV) using titration by hydrochloric acid $(\mathrm{HCl})$ and soil texture was plotted across a triangle that measues the proportions of sand, silt, and clay after separation by sedimentation (pipet method). Five uniform female trees with fruit production ability were selected in each habitat (as replications) and so five $200 \mathrm{~g}$ whole fruit samples were harvested in late October. Also, the height and diameter at $1.3 \mathrm{~m}$ height and crown diameter of trees in habitats were measured separately in every habitat and year. After drying the whole fruit samples (in an oven at $105^{\circ} \mathrm{C}$ for 12 hours), fruit oil was extracted using a soxhlet extractor for $5 \mathrm{~h}$ using petroleum ether as a solvent. The solvent was evaporated under reduced pressure, using a rotary evaporator at $50^{\circ} \mathrm{C}$. The oil content was determined as the difference in the weight of the dried fruit sample before and after the extraction (AOCS 1989). Oil was weighed and stored at $-20^{\circ} \mathrm{C}$. All of the analyses were conducted in triplicate.

\section{Statistical analyses}

Analysis of variance for $P$. atlantica fruit oil contents performed using two years' average data as the nested analysis method and means were compared using Duncan's multiple range test. Cluster analysis (using an agglomerative hierarchical method with standardized variables by subtracting the means and dividing by the standard deviation and dendrogram with the average linkage method and squared Euclidean distance) and principal component analysis (PCA) (using a correlation matrix and score plot for the first two components) were performed for the grouping and characterizing of $P$. atlantica habitats and the correlation coefficients between fruit oil content with recorded characteristics were also estimated.

\section{RESULTS AND DISCUSSION}

As shown in Table 1, the studied $P$. atlantica habitats were located at $1290-1750 \mathrm{~m}$ altitude, with $14-55 \%$ slope, $1.9-7.9^{\circ} \mathrm{C}$ average minimum temperature $\left(\mathrm{T}_{\text {min }}\right), 14.1-23.4^{\circ} \mathrm{C}$ average maximum temperature $\left(\mathrm{T}_{\text {max }}\right), 10.3-16.7^{\circ} \mathrm{C}$ average optimum temperature $\left(\mathrm{T}_{\mathrm{opt}}\right), 44-58 \%$ humidity, 442.1-788.4 and 1241-1371 mm annual rainfall and evaporation, 80-114 freezing days, 2725-2881 annual sunny hours, 7.1-7.4 soil $\mathrm{pH}$, 0.32-1.05 mmhos $\mathrm{cm}^{-1}$ soil electrical conductivity (EC), 5.1-29\% soil total neutralizing value (TNV), $0.8-7.1 \%$ soil organic carbon (OC), $20.2-43.2 \%$ soil clay and trees with 5.21-12.33 m height, $9.9-45.5 \mathrm{~cm}$ diameter at $1.33 \mathrm{~m}$ height and 4.79-10.15 m crown diameter. In addition, $P$. atlantica was developed in both forest areas associated with major species of Zagros such as Quercus spp., Amygdalus spp., Pyrus spp., etc. and in non-forest areas as a pure colony. According to the results, the ranges of ecological characteristics of $P$. atlantica habitats were wider than those of many other tree species, which suggests a high range tolerance of this plant against a range of ecological characteristic changes and an important cause for remaining across the hard dry climate in Iran during the last decades. In accordance to this, Rowshan et al. (2013) stated that $P$. atlantica is a drought-tolerant species that has adapted to semi-arid and arid areas.

The analysis of variance revealed significant differences $(p \leq 0.05)$ in the fruit oil content among locations (L) (Tab. 2). Because of the varying ecological conditions of the studied locations (seven areas involving almost all parts of the Kurdistan province), and also $P$. atlantica is a deciduous tree and highly heterozygous observed differences among locations were expected. The existence of significant differences among $P$. atlantica populations for fruit oil content was also reported by Hossein-Khan and Farhang (1996) and Arefi et al. (2003 and 2006). This variation can be due to both environmental and genetic factors and provide a suitable base for the selection of a superior population from the view point of fruit oil content. The mean of whole fruit oil was $27.3 \%$ with a range of $23.2-31.4 \%$ (Tab. 3). The results correspond to those reported by Arefi et al. 2003 and 2006 (19 to 39\%) and Hossein-Khan and Farhang 1996 (about $30 \%$ ) but are less than the results of Benhassaini et al. 2007 (39\%). The studied P. atlantica populations belonged to $P$. atlantica subsp. Kurdica, whose fruits are wider than $P$. atlantica subsp. mutica, thus the differences in fruit related traits, e.g. fruit dimensions and oil content are naturaly less and more, respectively. The fruit oil content data (with $n=35, S D=1.89, \bar{Y}=27.25$, AndersonDarling test $(A D)=0.55$ and $p=0.10$ ) follow a normal distribution. Among the studied locations, $P$. atlantica trees from the habitat of Borban produced the highest fruit oil, with $28.4 \%$, while trees from Allout produced the lowest fruit oil, with $25.4 \%$. P. atlantica habitats were divided in two high and low yield groups for the entire fruit oil content. The habitats of Borban, Khori-Abad, Kashtar and Gelah with 28.4, 28.4, 28.1 and 28.0\%, respectively, produced the highest whole fruit oil content, while 
Table 1. Select ecological characteristics of the research locations

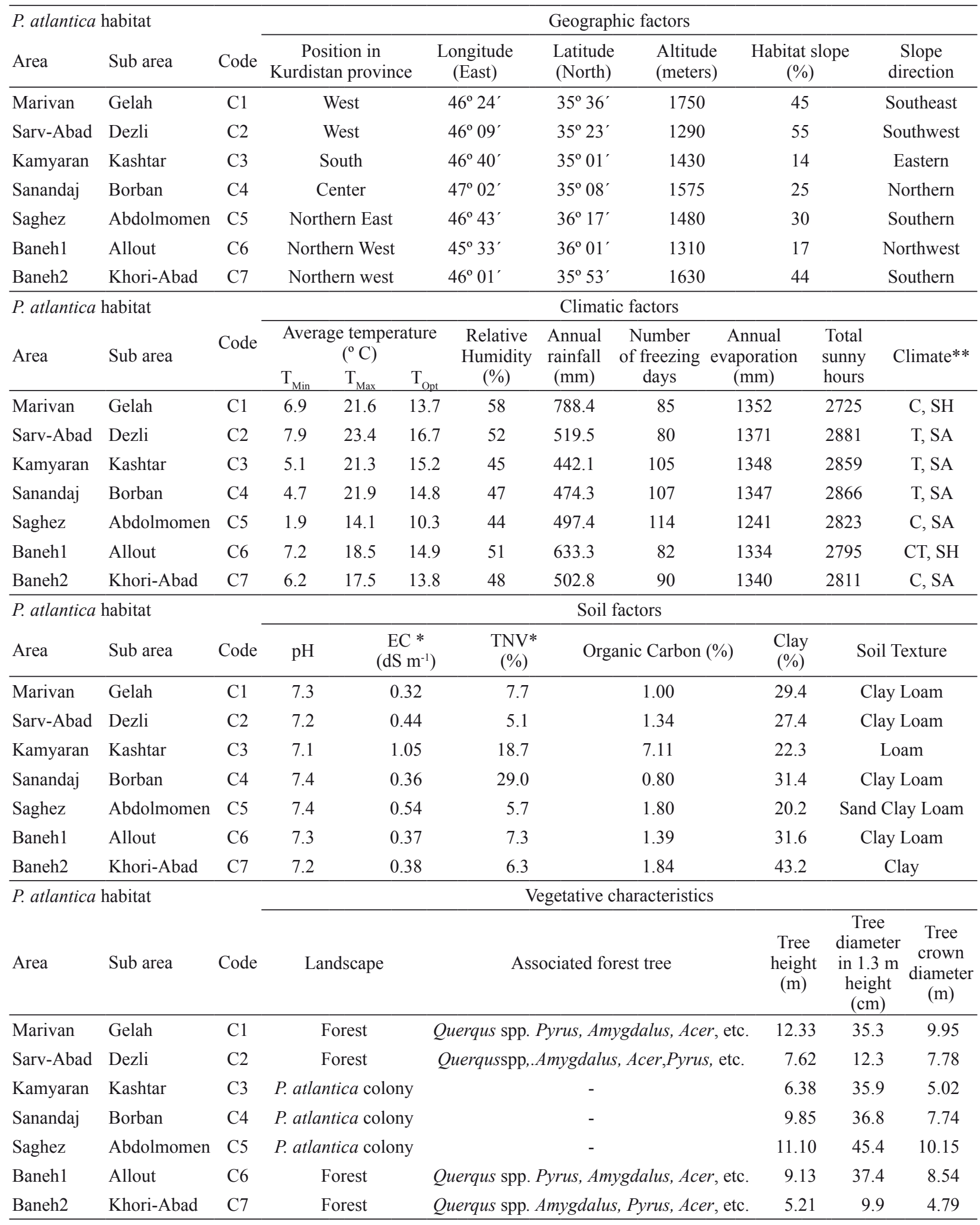

*EC: Electrical Conductivity (dS/m or deci Siemens per meter), TNV: Total Neutralizing Value (Lime material) (Percentage)

**T: Temperate: C: Cool, W: Warm, A: Arid, SA: Semi-arid, H: Humid. Yearly mean temperatures in warm, temperate and cool climates are $15-25^{\circ} \mathrm{C}, 10-15^{\circ} \mathrm{C}$ and $0-5^{\circ} \mathrm{C}$, respectively. Yearly mean rainfalls in semi-humid, semi-arid and arid climates are $600-$ $1400,300-600$ and 100-300 mm, respectively

the habitats of Allout, Abdolmomen and Dezli with $25.4,26.0$ and $26.4 \%$, respectively, produced the lowest content among the studied locations
(Tab. 3). There was wide ecological variation both between and within the two groups of high and low fruit oil yield locations. P. atlantica habitats 
Table 2. Analysis of fruit oil content variance over seven locations

\begin{tabular}{lccc}
\hline $\begin{array}{l}\text { Sources of } \\
\text { variation (SV) }\end{array}$ & $\begin{array}{c}\text { Degree of } \\
\text { freedom (DF) }\end{array}$ & $\begin{array}{c}\text { Sum of } \\
\text { squares (SS) }\end{array}$ & $\begin{array}{c}\text { Mean squares } \\
\text { (MS) }\end{array}$ \\
\hline Replication (R) & 4 & 3.50 & $0.87 \mathrm{~ns}$ \\
Locations (L) & 6 & 47.28 & $7.88^{*}$ \\
Error (E) & 24 & 71.38 & 2.97 \\
\hline
\end{tabular}

* and ns denote significant at $5 \%$ and nonsignificant, respectively

with higher fruit oil yield were mainly located in a higher longitude and altitude but with less latitude and slope and moderate temperature, both in a pure $P$. atlantica colony and associated with forest species (e.g. Querqus spp. Pyrus spp., Amygdalus spp., Acer spp., etc.), with medium yearly rainfall, evaporation and sunny hours but with more freezing days than that recorded for lower fruit oil yield trees. Yousefi (2002) stated that P. atlantica trees in forest areas such as the Marivan and Baneh populations in Kurdistan province produced larger leaflets, leaves and fruits than those in non-forest areas. It seems that the smallness and narrowing of leaves, leaflets and fruits in cold and dry areas is a tolerance mechanism to drought stress. The soil of high fruit oil yield habitats showed a higher salt concentration in the soil solution expressed as EC values, total neutralized value $(\% \mathrm{TNV})$, organic carbon content and clay and also medium vegetative traits, while trees of low fruit oil yield were larger and older. In accordance to this, longitude, altitude, maximum temperature, total neutralizing value and optimum temperature were significantly and positively correlated with fruit oil yield while latitude and tree crown diameter were significantly and negatively correlated with fruit oil yield (Tab. 4).

Seven $P$. atlantica habitats were grouped based on their ecological characteristics by using cluster analysis and the results is summarized are a dendrogram (Fig. 2). The sum of squares within clusters, average and maximum distances from the centroid were 126, 4.2 and 5.4, respectively. Based on the cluster analysis results, two habitats of Allout and Dezli showed the highest similarity among locations, with about $65 \%$. Finally, the habitats were classified into four distinct groups at $50 \%$ similarity. The habitats of Allout and Khori-Abad, Dezli and Gelah were located in the first group, Borban in the second, Kashtar in the third and Abdolmomen, with the highest distance from the other habitats, in the fourth group. All of the habitats in the first group were located in the forest areas of Baneh and Marivan in the west of Kurdistan and Iran on the border of Iraq with warmer temperatures, higher humidity and rainfall but fewer sunny hours and medium fruit oil content. The habitats of Borban

Table 3. $P$. atlantica fruit oil percentages and descriptive statistics in seven habitats

\begin{tabular}{|c|c|c|c|c|c|c|c|}
\hline Area & Sub area & Code & Max & Min & Range & Mean & CV $(\%)$ \\
\hline Marivan & Gelah & $\mathrm{C} 1$ & 29.1 & 25.9 & 3.2 & $28.0 \mathrm{a}$ & 5.1 \\
\hline Sarv-Abad & Dezli & $\mathrm{C} 2$ & 27.2 & 25.8 & 1.4 & $26.4 \mathrm{ab}$ & 2.4 \\
\hline Kamyaran & Kashtar & $\mathrm{C} 3$ & 30.2 & 25.7 & 4.5 & $28.1 \mathrm{a}$ & 6.6 \\
\hline Sanandaj & Borban & $\mathrm{C} 4$ & 31.4 & 26.8 & 4.6 & $28.4 \mathrm{a}$ & 6.7 \\
\hline Saghez & Abdolmomen & $\mathrm{C} 5$ & 28.4 & 24.4 & 4.0 & $26.0 \mathrm{ab}$ & 7.3 \\
\hline Baneh1 & Allout & C6 & 27.4 & 23.2 & 4.2 & $25.4 \mathrm{~b}$ & 7.9 \\
\hline Baneh2 & Khori-Abad & $\mathrm{C} 7$ & 30.2 & 26.8 & 3.4 & $28.4 \mathrm{a}$ & 4.5 \\
\hline Total & - & & 31.4 & 23.2 & 3.6 & 27.3 & 5.8 \\
\hline
\end{tabular}

Means with different letters show significant differences at $5 \%$ probability

Table 4. Correlation between fruit oil percentage and other characteristics

\begin{tabular}{|c|c|c|c|c|c|c|c|c|c|c|c|c|c|c|c|c|c|c|c|c|}
\hline & 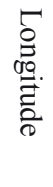 & $\begin{array}{l}\text { 氧. } \\
\text { 芑 } \\
\text { مै }\end{array}$ & 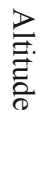 & $\frac{\mathscr{N}}{\frac{0}{0}}$ & 䯧 & $\underset{\substack{0 \\
x}}{\stackrel{1}{3}}$ & 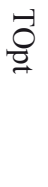 & 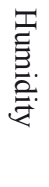 & 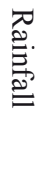 & 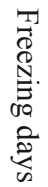 & 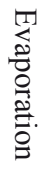 & 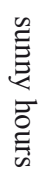 & 导 & $\stackrel{T}{\Omega}$ & 光 & $\stackrel{\ominus}{\Omega}$ & $\stackrel{\Omega}{\stackrel{\nu}{\nu}}$ & $\begin{array}{l}\exists \\
\stackrel{8}{8} \\
\mathbb{D}\end{array}$ & $\begin{array}{l}\vec{\sigma} \\
\stackrel{8}{8} \\
\dot{\sigma} \\
\dot{\sigma}\end{array}$ & $\begin{array}{l}\exists \\
\overrightarrow{8} \\
\beta \\
\theta\end{array}$ \\
\hline Fruit oil & 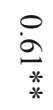 & $\begin{array}{l}\dot{D} \\
\stackrel{1}{\sim} \\
* \\
*\end{array}$ & $\begin{array}{l}\stackrel{0}{N} \\
\stackrel{N}{*} \\
*\end{array}$ & $\begin{array}{l}0 \\
0 \\
0 \\
\ddot{E}\end{array}$ & $\begin{array}{l}\dot{b} \\
0 \\
\stackrel{0}{\Xi}\end{array}$ & $\begin{array}{l}\stackrel{0}{u} \\
* \\
* \\
*\end{array}$ & $\begin{array}{l}\circ \\
\stackrel{+}{a} \\
*\end{array}$ & $\begin{array}{l}\dot{0} \\
0 \\
0 \\
\overrightarrow{\theta^{2}}\end{array}$ & $\begin{array}{l}\dot{b} \\
\dot{\omega} \\
\overrightarrow{\omega^{2}}\end{array}$ & \begin{tabular}{l}
0 \\
N \\
\multirow{E}{*}{}
\end{tabular} & $\begin{array}{l}\stackrel{0}{ \pm} \\
\stackrel{ \pm}{E} \\
\vec{E}\end{array}$ & $\begin{array}{l}\dot{b} \\
\stackrel{0}{0} \\
\overrightarrow{\sigma^{2}}\end{array}$ & $\begin{array}{l}\dot{b} \\
\stackrel{N}{+} \\
\vec{E}\end{array}$ & $\begin{array}{l}\stackrel{0}{\vec{D}} \\
\stackrel{\vec{\Delta}}{\Delta}\end{array}$ & $\begin{array}{l}0 \\
\dot{u} \\
* \\
*\end{array}$ & $\begin{array}{l}0 \\
\text { u } \\
\text { : } \\
\dot{w}\end{array}$ & $\begin{array}{l}0 \\
\dot{w} \\
\curvearrowright \\
\ddot{\omega}\end{array}$ & $\begin{array}{l}\dot{b} \\
\text { 心 } \\
\text { z }\end{array}$ & $\begin{array}{l}\dot{b} \\
\text { N } \\
\text { E }\end{array}$ & $\begin{array}{l}\dot{0} \\
\text { un } \\
*\end{array}$ \\
\hline
\end{tabular}

$* * *$ and ns denote significant at $1 \%, 5 \%$ and nonsignificant, respectively 


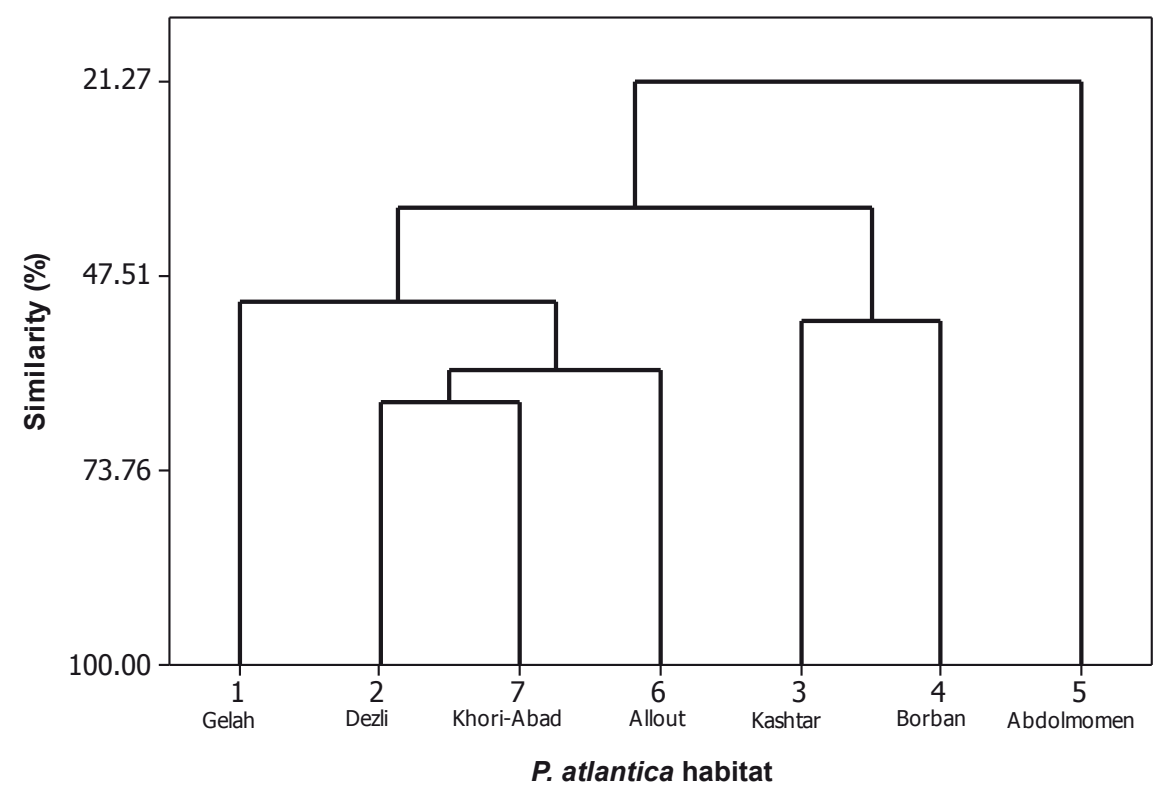

Figure 2. Dendrogram of cluster analysis based on the ecological characteristics of $P$. atlantica habitats

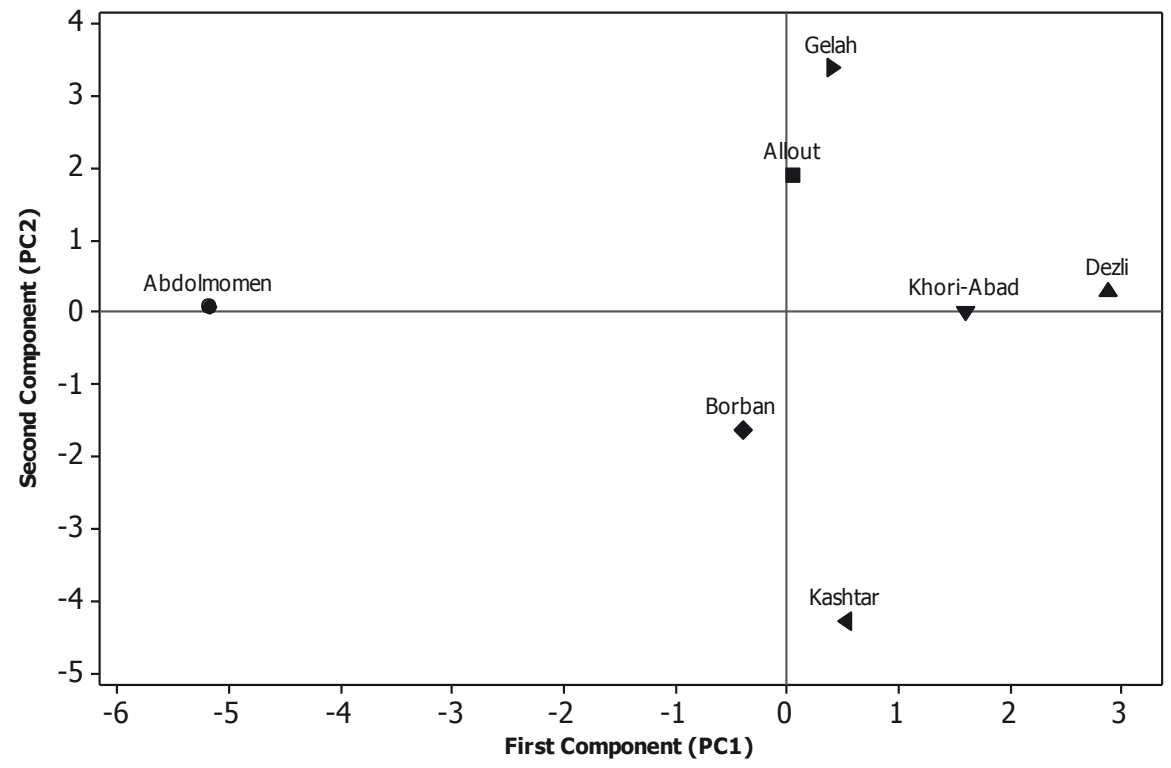

Figure 3. Score plot for the first two components of principal component analysis (PCA)

and Kashtar in groups two and three were located in non-forest areas in the center of Kurdistan with a higher longitude, altitude, maximum and optimum temperature, TNV and produced the highest fruit oil content, with more than $28 \%$. The habitat of Abdolmomen (group four) showed less than 22\% similarity with the other habitats, and was located in the northern non-forest areas of Kurdistan with the coldest climate, the least soil TNV and clay with the oldest $P$. atlantica trees and low fruit oil yield.

The result of principal component analysis (PCA) revealed that the five first PC with 6.54,
$6.02,3.29,2.27$ and 1.77 eigen values, respectively, covered $95 \%$ of total variance. The score plot for the first two components (Fig. 3) is in accordance to the dendrogarm of cluster analysis. All of the $P$. atlantica habitats of the first group had positive $\mathrm{PC}_{1}$ and $\mathrm{PC}_{2}$. The habitats with low fruit oil content such as Allout, Abdolmomen and Dezli showed extreme values (positive or negative) of $\mathrm{PC}_{1}$ and $\mathrm{PC}_{2}$, but the habitats with high fruit oil content such as Borban, Khori-Abad and Ksshtar, located mainly in central zones of the bi plot, suggest that the $P$. atlantica habitats with medium ecological 
conditions (medium temperatures, rainfall, slope, freezing days, sunny hours, tree height, diameter and age, etc.) produce higher fruit oil.

\section{CONCLUSIONS}

1. A relatively small variation in oil content in fruits across plants of $P$. atlantica was found. The fruit oil content ranged from $25.4 \%$ to $28.4 \%$.

2. Most of the $P$. atlantica habitats in the western and central part of Iran belonging to temperate and semi-arid regions, with higher longitude and altitude but less latitude and slope, higher soil electrical conductivity, total neutralizing value, organic carbon and clay, medium yearly rainfall, evaporation and sunny hours, and also trees with medium ages such as Borban and Kashtar produced higher fruit oil yields than those that belonged to cool and semi-humid regions.

3. Cluster analysis classified habitats into four distinct groups at 50\% similarity. Four habitats belonging to forest areas were located in the first, Borban and Kashtar in the second and third and Abdolmomen, with the coldest climate and the oldest trees, was in the fourth group.

4. The results of principal component analysis (PCA) revealed that habitats with lower fruit oil showed extreme values of PC1 and PC2 but ones with higher fruit oil were located mainly in the central zones of the bi plot, which suggest that habitats with medium ecological conditions produce higher fruit oil.

\section{ACKNOWLEDGEMENT}

The author is grateful to Avin and Barbod and Bardia Yousefi for their assistance in data collection and analyzing.

\section{FUNDING}

The presented research was supported by the Agricultural and Natural Resources Research Center of Kurdistan province (Iran).

\section{CONFLICT OF INTEREST}

Authors declare no conflict of interest.

\section{REFERENCES}

AOCS, 1989. Official methods and recommended practices of the American Oil Chemist's Society. Champaign: American Oil Chemist's Society, Method Ce-66, USA.
Arefi H., Nasir Yadeh A., Miryaei-Nodushan H., 2003. Variation in base line maternal and paternal $P$. atlantica tree (Pistacia atlantica). Proceedings of the Second National Conference of $P$. atlantica tree. Iranian J. For. Poplar Res. 10(2): 405-419.

Arefi H.M., Abdi A., Saydian S.E., Nasir Zadeh A., Mirzaei-Nodoushan H., Rad M.H., 2006. Genetics and breeding of Pistacia atlantica in Iran. Acta Hort. 726: 77-81.

Ben Douissa F., Hayder N., Chekir-Ghedira L., Hammami M., Ghedira,K., Mariotte A.M., et al., 2005. New study of the essential oil from leaves of Pistacia lentiscus L. (Anacardiaceae) from Tunisia. Flavour Fragrance J. 20: 410-414.

Benhassaini H., Bendahmane M., Benchalgo N., 2007. The chemical composition of fruits of Pistacia atlantica DESF. Subsp. atlantica from Algeria. Chem. Nat. Compd. 43(2): 121-129.

Dogan O., Baslar S., Aydin H., Mert H.H., 2003. A study of the soil-plant interactions of Pistacia lentiscus L. distributed in the western Anatolian part of Turkey. Acta Bot. Croat. 62(2): 73-88.

Farhoosh R., Haddad Khodaparast M.H., ShariF A., 2009. Bene hull oil as a highly stable and antioxidative vegetable oil. Eur. J. Lipid Sci. Technol. 111: 1259-65.

Farhoosh R., Tavassoli-Kafrani M.H., Sharif A., 2011. Antioxidant activity of the fractions separated from the unsaponifiable matter of bene hull oil. Food Chem. 126: 583-9.

Ghalem B.R., Mohamed B., 2010. Antimicrobial activity determination of the gum of Pistacia atlantica Desf. oil. African J. Microbiol. Res. 4: 2457-2460.

Hossein-Khan R., Farhang B., 1996. Pistacia mutica: A new resource for oil production. Seminar on pistachio problems, 20-22 August 1996, Kerman, Iran: 71-76.

Ibrahim I.H., Nahlawi,N., Nahlawi M., 1984. Pistacio rootstocks studies under arid zone conditions. ACSAD. Izraa Research Station, Syria, 44 pp.

Isfendiyaroglu M., OzeKera E., 2009. Inflorescence features of a new exceptional monoecious Pistacia atlantica Desf. (Anacardiaceae) population in the Barbaros Plain of İzmir, Turkey. Int. J. Plant Prod. 3(3): 93-98.

Karimi H.R., Zamani Z., Ebadi A., Fatahi M.R., 2009. Morphological diversity of Pistacia species in Iran. Genet. Resour. Crop Evol. 56 (4), 561-571.

Khatamsaz M., 1988. Flora of Iran, Anacardiaceae. No: 3. Research Institute of Forests and Rangelands (RIFR).IR.Iran, $22 \mathrm{p}$.

Mezni F., Labidi A., Msallem M., Boussaid M., Khouja M.L., KHALdi A., 2014. Influence of harvest date on fatty acid composition and antioxidant activity of Pistacia lentiscus L. edible oils. J. Mater. Environ. Sci. 5(6): 1703-1708.

Pourreza M., Shaw J.D., Zangeneh H., 2008. Sustainability of wild pistachio (Pistacia atlantica 
Desf.) in Zagros forests. Iranian For. Ecol. Manag. 255: 3667-3671.

Razavi S., 2006. Pistachio production, Iran vs. the World. Acta Hort. 726: 689-694.

Rowshan V., Bahmanzadegan A., Tarakemeh A., 2013. Volatile compounds of pistacia atlantica Desf. galls and leaves by Combi-PAL system technique. Technical Journal of Engineering and Applied Sciences 3(9): 796-798.

Ruelas Garcia S., 1990. Grafting methods in pistachio (Pistacia vera L.). Proceedings of the Tropical Region. American Society for Horticultural Science, Unda, 23: 50-53.

Soad S.N.J., Abdulkareem M.H., Salimon J., 2014. Physicochemical assessment of the Libyan Pistacia atlantica Desf. fruit oil. Int. J. Chem. Mol. Eng. 1(8), scholar.waset.org/1999.17/13971.

Tanideh N., Masoumi S., Hossainzadeh M., Safarpour A.R., Erjaee H., Koohi-Hossainabadi O., Rahimikazerooni S., 2014. Healing Effect of Pistacia atlantica fruit oil extract in acetic acid-induced colitis in rats. Iranian J. Med. Sci. 39(6): 522-528.
Tohidi M., Khayami M., Nejat, V., Meftahizade H., 2011. Evaluation of antibacterial activity and wound healing of $P$. atlantica and Pistacia khinjuk. J. Med. Plants Res. 5(17): 4310-4314.

Villar A., Sanz M.J., Paya M., 1987. Hypotensive effects of Pistacia lentiscus L. Int. J. Crud Drug Res. 25: $1-3$.

Yousefr B., 2002. A comparative study of the ecological and genetically characteristics of $P$. atlantica tree populations in Kurdistan province. Iranian J. For. Poplar Res. 26 (7): 65-99.

Walkley A., Black I.A., 1934. An examination of degtjareff method for determining soil organic matter and a proposed modification of the chromic acid titration method. Soil Sci. 37: 29-37.

ZAngeneh H., 2003. Ecological requirements of Pistacia atlantica in Kermanshah Province. Iranian Journal of Forest and Poplar Research. Special issue: The Second National Symposium on Wild Pistachio 333: $122-130$

Received November 24, 2015; accepted February 23, 2016 